\title{
The development of mathematical abstraction in the nursery
}

\section{Maulfry Worthington ${ }^{1} \cdot$ Marjolein Dobber $^{2} \cdot$ Bert van Oers $^{3}$}

Published online: 27 June 2019

(C) The Author(s) 2019

\begin{abstract}
The aims of this article are to document the types of signs that young children make to represent their mathematical thinking, and to determine the extent to which features of usagebased language acquisition are evident in children's early graphical communications made in mathematical contexts. Studies of young children's symbolic principles in ontogeny and research into the acquisition and development of language provide insights into the rich foundational knowledge on which they build their early mathematical inscriptions. The study conceives of children's mathematical abstractions as emergent cognitive representations, originating in their need to communicate within personally meaningful contexts. The collected ethnographic data comprise mathematical inscriptions from seven children aged three to four years in their nursery school and written observations from their teachers and the first researcher. Analysis follows an interpretive, social-semiotic paradigm; the inscriptions were analysed to show how they convey their emerging mathematical understandings, and how this supports their emergent abstractions. The findings illuminate children's strategies as they communicate their thinking, indicating the importance of symbolic number knowledge in acquiring the abstract graphical language of mathematics.
\end{abstract}

Keywords Abstraction · Grammaticisation · Usage-based language acquisition · Signs · Children's mathematical graphics $\cdot$ Nursery school

Maulfry Worthington

maulfry@blueyonder.co.uk

1 Department Theory and Research in Education, Vrije Universiteit Amsterdam, van der Boechorststraat 7, $1081 \mathrm{BT}$, Amsterdam, the Netherlands

2 Vrije Universiteit Amsterdam, Amsterdam, the Netherlands

3 Cultural Historical Theory of Education, Vrije Universiteit Amsterdam, Amsterdam, the Netherlands 


\section{Introduction}

An important aim of education is teaching children to communicate about their abstractions in a culturally agreed form. However, the formal representations of mathematical abstraction are widely recognised as challenging for children to achieve, Ginsburg (1977) identifying difficulties in mathematics as partly relating to their problems with written symbolism. Hiebert (1984) concurred, declaring that school mathematics,

is much different from the intuitive and informal mathematics the children acquire... many of the children's observed difficulties can be described as a failure to link the understandings they already have with the symbols and rules they are expected to learn. (p. 498/501)

In school, children are confronted with formal mathematical language without explanation of the point of view from which this can be seen as valid or consistent. Traditionally taught mathematics "becomes mainly a process of manipulation of numbers" (Nunes, 1993, pp. 197-198), often lacking meaningful connections between children's personal cultural knowledge and understandings. Van Oers (2012) warns that early imposition of abstract signs can cause alienation from school subjects ( $\mathrm{p}$. 137), resulting in children adopting superficial features, unable to transform them into a personally meaningful system (Ernest, 2005, p. 25). In contrast, our study argues that an approach in which children can socially connect their existing cultural knowledge and integrate signs introduced by their teacher contributes useful foundations for mathematics in school. Indeed, Morgan (2006) contends that from a social semiotic perspective, learners' thinking and meaning-making

is not simply set within a social context but actually arises through social involvement in exchanging meanings... the relationship between the individual and the social compatible, Hodge and Kress (1988) argue, with the theories of Volosinov and Vygotsky. (p. 221)

Considerable changes in government policies in England (e.g., DfE, 2017) imply that children's inscriptions are unlikely to be recognised, or their meaning-making supported (Carruthers, 2015; Moffett \& Eaton, 2018; Williams, 2008). Based on the belief that children's learning is always socially constructed, this omission makes it essential that this current study be conducted.

An extensive body of research exists into young children's emergent beginnings with writing (e.g., Clay, 1975; Kress, 1997), with some studies into emergent signs for mathematics (e.g., Brizuela, 2004; Carruthers \& Worthington, 2005, 2006; Hughes, 1986; Tolchinsky, 2003). Munn (1994) upholds a view of children's functional use of signs for mathematics as "essentially a literate strategy" (p. 13). However, neither the beginnings of children's own notations made in mathematical contexts, nor their progress into abstract sign use have previously been interrogated. Investigating children's signs from a Peircian perspective (Buchler, 1955), coupled with a usage-based view of language acquisition (Langacker, 2008; Tomasello, 2005), may help establish 
their emergent mathematical abstractions (which for young children extend beyond understanding of numbers).

\subsection{Abstraction}

Abstraction is widely conceived as a human ability to focus on relationships through formal language and symbolic representations. Mathematical signs are analogous with inscriptions, notations, symbolic tools, emergent models, representations, and (from Carruthers \& Worthington, 2005) children's mathematical graphics.

An important aspect of mathematics is its cultural symbolic system in which mathematical symbols execute a dual function, supporting personal thinking and providing communicative tools. The German philosopher Ernst Cassirer suggested a seminal solution to explain abstraction, proposing that abstraction is projected into differing objects by seeing them as related from a specific point of view, consistently focusing on a specific relationship that can be seen as connecting all objects attended to, and, by the same token neglecting all aspects that fall outside this focus. Words, drawings, and marks help children to focus on relationships they see as relevant for representation. As we will show, children's inscriptions transpire to be productive in assisting them to express their (abstract) view on their world.

\subsection{Peirce's perspective}

The present study draws on Peirce's semiotic theory to analyse and interpret children's early signs, investigating ways in which they indicate meanings recognised as mathematical by others in their community.

In Peirce's terms, iconic signs have some resemblance to the object signified. The term symbolic refers to conventional signs (e.g., letters, numerals). Indexical refers to something directly connected to that which is signified. Children's ostensive signals draw attention to and help clarify their intentions, rendering the "act of reference... a social one" (Werner \& Kaplan, 1963, p. 43). Csibra and Gergely (2011) established that infants' sensitivity to others' ostensive gestures such as direct eye contact and speech prepares them "to identify and interpret others' actions as communicative acts specifically addressed to them" (p. 1150). Children's often-isolated early signs develop over time into rule-based structures (Langacker, 2008), to be interpreted as a process of grammaticisation, following a usage-based theory of language acquisition. According to Tomasello (2005), language structure emerges "from language use... patterns of use emerge and become consolidated into grammatical constructions" (p. 5). The mathematical realisation of this theory provides insights into children's growing ability to engage in intention-reading, locating (grammatical) patterns in their graphical communications.

\subsection{Language acquisition}

Using signs for expressing an abstract view, people often combine different signs according to some basic rules. Joint attention facilitates the first feature intention-reading, in which 
individuals focus on others' behaviour and speech, helping them determine how they might contribute to their shared activity.

The second feature is functional, meaning-related pattern-finding:

to learn the conventional use of a particular word [or sign] the child not only must discern across instances that it is the same... but must also see the way adults use a particular form communicatively across different usage events. (Tomasello, 2005, pp. $30-31)$

Tomasello likens pattern-finding to children's ability "to create analogies (structure mappings) across two or more complex wholes, based on similar functional roles" (p. 4), understood here as how this particular sign 'works' to convey my meaning.

Lancaster (2014) found two- to three-year-old children's beginnings in using a systematic structure in their drawings, enabled them to devise "independent and original solutions... in the face of complex symbolic problems" (p. 45), identifying "marks such as lines, dots, or zigzags being used to show... quantity, as with number" (p. 37). Worthington (2009) identified patterns of sign-use three- to fouryear olds adopted in drawings, suggesting a continuation of sign-use from children in Lancaster's study, and indicating that this usage-based theory may also be successfully investigated in graphical contexts such as mathematics. Significant for the current study is the finding that between the ages of three to four years, the children had begun to spontaneously use abstract signs, a feature also identified by Machón (2013).

In studying the emergence of mathematical abstractions, we assumed children's participation in everyday cultural practices supported their mathematical communications. Hence, we first investigated the cultural foundations of mathematics (Worthington \& van Oers, 2016). Sarama and Clements (2008) highlight "five major mathematical topics [...] number and arithmetic, geometry, measurement, patterning and algebraic thinking, and data and graphing" (p. 67), all of which may include aspects of number. MacDonald (2013) investigated children's ideas about measuring length. Worthington and van Oers (2016) found that aspects of mathematics the children most frequently explored were number, time, and money, followed by wider aspects of mathematics, all made on their own initiative. ${ }^{1}$

Exploiting their existing cultural knowledge of mathematics and sign-use, the children expanded their understandings in pretend play. For example, at home, Isaac and his dad often went camping: subsequently, in one play episode, Isaac focused on the number of nights booked, the fee for camping, and the number of people staying. Interrogating the same data, a second study explored the children's drawings, maps, and writing in which they made considerable use of their cultural knowledge of authentic literacy practices at home (Worthington \& van Oers, 2017) in meaningful literacy events within pretend play, locating a similar range of modes, materiality, and affordances to those identified in the current study. The present study is situated within current research on semiotics and multimodality related to mathematics (e.g., Cobb, Yackel, \& McClain, 2000). Presmeg (2006) highlights the potential of semiotic chaining "to bridge [the] apparent gap" between learners' existing understandings and taught concepts (p. 164), identified

\footnotetext{
${ }^{1}$ The children's frequent references to time and money are considered to underscore their significance in the children's home experiences (Worthington \& van Oers, 2016, p. 59).
} 
here in some of the children's own notations which themselves become peer models, contributing to their cumulative collective repertoires. ${ }^{2}$

\section{Young children's graphical, mathematical semiotic activity}

Young children often exceed adults' expectations of their ability to represent abstract symbolic thinking (Brizuela, 2004). Research into children's sign-use to communicate mathematical ideas include Hughes's seminal work (Hughes, 1986), establishing that young children make sense of mathematical notations relating to number, provided they are free to represent them in personally meaningful ways. This, he proposed, could help children translate between "this new language" and their concrete knowledge (p. 51).

Drawing on Vygotsky's work, van Oers (e.g., van Oers, 2012) has investigated children's schematisations as foundations for later mathematical representations. This dialectical, social process is based on teachers' interventions in their play, in which children construct useful means (signs, inscriptions) for communication, the relationship between concrete and abstract elaborated through dialogue (van Oers, 2001). Also, from a Vygotskian perspective, during the 1990s, Carruthers and Worthington (e.g., Carruthers \& Worthington, 2005, 2006) began investigating mathematical signs and texts of children from two to eight years in natural, everyday contexts of homes and classrooms. They found that children's signs are often integral aspects of contexts in which they are free to use their own representations, such as pretend play.

Vygotsky (1978) understood pretend play as "a major source of development" (pp. 102103 ) for young children, laying the foundations of abstract symbolism. Children learn to use socially valued conventions related to mathematical signs from family members and teachers who frequently model signs (within multi-sign utterances). ${ }^{3}$ This study extends Carruthers and Worthington's earlier research, building on that of Worthington and van Oers $(2016,2017)$ and addresses the following research questions:

RESEARCH QUESTION 1: What range of signs do pre-school children use to communicate their mathematical thinking?

RESEARCH QUESTION 2: How does children's intention-reading relate to increases in acquisition of the abstract symbolic language of mathematics?

RESEARCH QUESTION 3: How does children's pattern-finding support their increasing grammaticisation?

Regarding the outcomes of our investigations, we expect that the answers are predicated on the conditions that children are allowed to freely engage in graphicacy in all contexts.

\footnotetext{
${ }^{2}$ Comment made by the teacher Emma.

${ }^{3}$ Over time, teachers attach explicit mathematical meanings to the children's signs, engaging with them in dialogue and referring to where (from contextual clues or the child's vocal explanation) their marks and signs suggest aspects of mathematics.
} 


\section{Methodology}

\subsection{Research setting and participants}

The research setting is a nursery school located in Bristol, a large multicultural city in South-West England: 60 children attend each half-day session, individual key persons leading each group of approximately 14 children. Led by the headteacher, this nursery school had pioneered the approach to mathematical representation developed by Carruthers and Worthington: mathematics and graphicacy have high profiles, children frequently using their own signs to communicate ideas. ${ }^{4}$ The headteacher of this nursery school co-researched and developed the educational concept on which this study draws. Working with the headteacher, the teachers developed their understandings of mathematics and sign-use over several years. The first author had also previously led professional development on this approach at the nursery, both teachers in the study attending.

The nursery advocates a democratic culture, valuing and supporting children's ideas, choices, and decisions and how they express them. As the only nursery school identified sharing these values, this nursery was selected for this study. ${ }^{5}$ Children self-initiate their mathematical ideas through play indoors and out, and in adult-led small groups. ${ }^{6}$ As more knowledgeable others, adults notice and recognise children's language and graphics as mathematical; the teachers involved in this study are acknowledged as "expert" teachers in this.

Ethnographic data were gathered of seven children. To determine if previous interest in graphicacy influenced their interest in communicating through inscriptions in mathematical contexts, teachers Emma and Hugo were asked to identify several children who often chose to draw or write. Nominating Isaac, Shereen, and Elizabeth as focal children, their teachers randomly selected four other children for comparison (Oliver, David, Ayaan, and Tiyanni): their ages ranged between three years and two months to four years and would start school the following year. Shereen's family is from the Philippines and Tiyanni's from the West Indies: both speak English fluently. Ayaan's family is Somalian: she speaks fluent Somali, her confidence in spoken English is growing. The remaining children's first language is English.

\subsection{Research design}

This is a longitudinal, ethnographic study: Zaharlick (1992) describes ethnography's value as aiding understanding of "beliefs, attitudes and behaviours of sociocultural groups" (p. 122), to support improvements in education. Field notes on the children's home cultural knowledge were gathered from parents and teachers. Geertz (1973) asks how we might "frame an analysis of meaning - the conceptual structures individuals use

\footnotetext{
${ }^{4}$ The headteacher is engaged in doctoral research on the pedagogy of this approach (see Carruthers, in progress).

${ }^{5}$ During a period of 2 years (prior to collecting data in this nursery), the first author made numerous visits to a total of 12 classrooms (in 7 schools), with the intention of data gathering. However, almost no useful examples of children's spontaneous mathematical notations were identified in these classes.

${ }^{6}$ Examples from the data were gathered from both contexts.
} 
to construe experience - which will be at once circumstantial enough to carry conviction and abstract enough to forward theory" (p. 313). According to Geertz, we must isolate elements of the culture studied, establishing its inner relationships to identify "the ideological principles upon which it is based" (p. 17). This idea influenced this study and its analyses, revealing a broad appreciation of the symbolic principles involved, and also previously hidden elements of grammaticisation as children moved towards conventional signs of the established mathematical culture.

Multiple naturalistic and unstructured observations of seven children are supplemented by information from parents and teachers. Due to their ecological validity and grounding in authentic contexts, observations are particularly suitable for our ethnographic research. ${ }^{7}$ The teachers' established practice is to record children's behaviours and talk as they occur. This is a theory-driven observational study of one case, of one specific nursery school, in which we focus on seven children.

\subsection{Procedure: data sources}

Data were collected during the course of one year, primarily from the teachers' written observations in the children's learning diaries. The first author also made observations during a total of 65 visits to the nursery. ${ }^{8}$ According to our view of abstraction as a process of consistent perspective taking, naturalistic observations can be considered relevant as they can reveal the children's point of view on a situation. Our theorydriven observations make our interpretations of these observations conceptually valid. Most observations are of pretend play, with several from adult-led small groups (e.g., Fig. 1). The headteacher led regular professional development, staff members developing their skills in documenting observations. Conforming to government requirements, the headteacher regularly moderated their written observations.

In addition to the written observations, the data comprise photographs of the children's graphics and field notes of informal discussions with parents and teachers. To ensure maximum validity, the children's graphics are analysed in conjunction with the written observations. Single visits to each child's home enabled the first author and the parent/s to become acquainted. ${ }^{9}$ Together, these sources provided background information on the children's experiences and cultural knowledge.

\subsection{Data collection and analysis}

Data are examined from several perspectives to affirm how children create meaningful communicative signs, especially for those parts of their everyday lives generally acknowledged as mathematical. Accordingly, our study takes an interpretive stance, combining social

\footnotetext{
${ }^{7}$ In England, throughout the early years, foundation stage (birth-5 years), daily use of written observations are used as formative assessment, and have been established for some years at this nursery school. Early year settings are required by the government to collect and submit details of each child's achievement in respect of specified areas of learning.

${ }^{8}$ Occasionally, the first author observed with one of the teachers, discussing afterwards what they had understood from their observations and identifying a similarity in them.

${ }^{9}$ For personal family reasons, it was not possible to visit one of the children at home. Home visits are an accepted practice in this nursery, helping the child and her parent/s develop a relationship with the teacher.
} 
semiotic and language development perspectives. The first codes (relating to research question one) arose from Peirce's categories: iconic, symbolic, and indexical (Buchler, 1955), necessitating a new code for early mathematical marks and sub-codes to differentiate between the various modalities identified. To confirm inter-rater reliability, a second coder coded a randomly chosen $20 \%$ of the children's inscriptions, achieving a $100 \%$ consensus. For questions two and three interpretive analyses allowed identification of episodes in which intention-reading and pattern-finding were evident. Coding signs throughout all their literacies was achieved through using computer-assisted qualitative data analysis software, enabling consistent identification. A second coding of the children's signs made in mathematical contexts highlighted those using iconic signs and those representing abstract numerals and indices.

Data were open and derived from the field, elemental coding employed to identify the children's mathematical inscriptions, which were then coded as a distinct set of data for the purposes of this study.

\subsection{Ethics}

Guided by BERA's ${ }^{10}$ ethical principles (2011) and those of Vrije Universiteit Amsterdam (VU University, 2014), participants were informed and consulted at every stage, and permissions sought from all who would be involved. The headteacher and teachers gave their consent for gathering data in the nursery. At the onset of the research, parents' informed consent to observe their child and collect data was sought in writing. The research was explained to the children using everyday language and their agreement requested. Parents were informed that they could withdraw their child from the research at any time, and one family did so early in the period of data collection: no data pertaining to this child have been used.

\section{Results}

To determine which of the children's graphical communications were mathematical, contexts in which they referred to aspects of mathematics were identified. Especially notable is that their mathematical signs and texts combined simplicity and utility rather than elaborate drawings. They explored a wide range of mathematical genres to communicate comprehensive aspects of mathematics. Of the three focal children, Shereen favoured shopping lists, receipts, and orders in cafes, whilst Isaac made signs for a car park, campsite bookings, and maps and plans. Elizabeth's interests were broad and the proportion of all her graphics less often mathematical. ${ }^{11}$ David (a non-focal child) also communicated his mathematical thinking through a high number of mathematical texts (Table 1). Thirty-three percent of all the graphics were considered mathematical.

\footnotetext{
${ }^{10}$ The British Educational Research Association

${ }^{11}$ Elizabeth's abiding interest in signs for writing was evident in her earlier learning diaries when she first attended nursery before she was two years old.
} 
Table 1 Showing quantities of each child's mathematical texts in the year

\begin{tabular}{llllllll}
\hline Isaac & Shereen & Ayaan & David & Oliver & Elizabeth & Tiyanni & Totals \\
\hline 19 & 13 & 6 & 17 & 12 & 10 & 2 & 79 \\
\hline
\end{tabular}

RESEARCH QUESTION 1: What range of signs do pre-school children use to communicate their mathematical thinking?

Early mathematical marks Of all the inscriptions, $19.0 \%$ were scribble-marks, acknowledged by Carruthers and Worthington (2006) as shorthand for communicating meanings, and suggesting they allow play to continue without interruption (Worthington \& van Oers, 2017). Werner and Kaplan (1963) refer to such symbols as "protosymbols" that "directly "present" a meaning rather than "represent it" and "extremely important in the genetic process of symbolization" (pp. 42-43, emphasis in the original). Price, Jewitt, and Crescenci (2015) consider the "meaning" of such marks "initially only available to the child [...] as their symbolic understanding progresses [they] become more recognizable to others" (p. 132), for example:

Standing on the bathroom scales David looked at the numeral on the dial, remarking, 'I'm ' 15 ', so I need to write it down' and made some letter and numeral-like signs on the whiteboard. Making rapid scribble-marks on paper, Isaac used his emergent knowledge of various measuring units explaining, 'David weighs 700 kilos, he's sixty metres heavy' (Fig. 1).

Taking a specific point of view, the children's intention focused on communicating about number and weight, neglecting all aspects that fall outside this focus: from our view of quantity and measurement, scribbles can be seen as an early form of abstraction. However, these are not abstract symbols, consistently referring to specific meanings from a certain point of view, and Isaac's use of the language of measurement does not imply that he had established conceptual understanding of the amounts to which he referred. In early childhood, children's meaning-making shows this is a very versatile process, their willingness to communicate through signs more significant than the ability to write neat numerals (Brizuela, 2004).

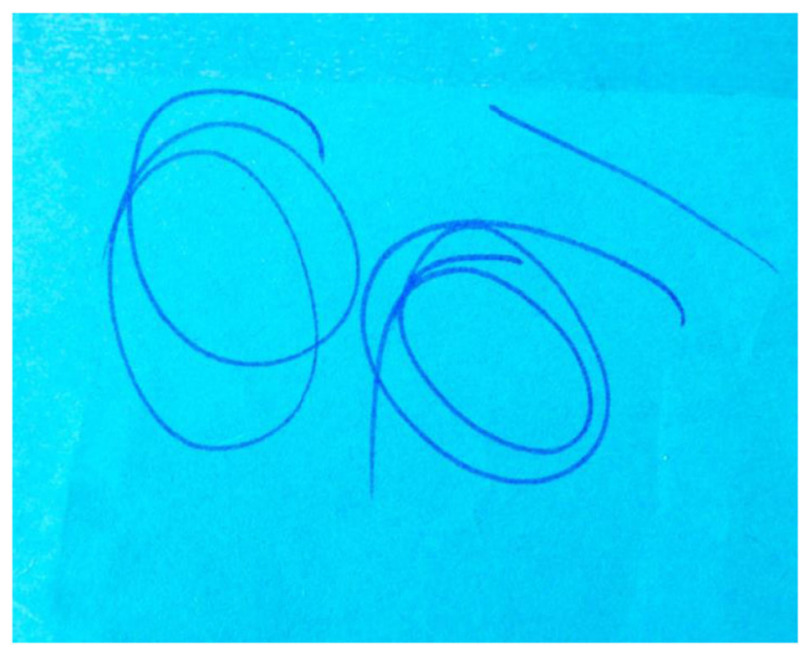

Fig. 1 "David weighs $700 \mathrm{k}$ " 
Analysis of the data from a Peircian viewpoint highlighted the percentage of signs in three categories that the children used when approaching their environment from a specific (mathematical) point of view.

\subsection{Iconic signs}

$49.3 \%$ of the children's signs were iconic, Fay, Ellison, and Garrod (2014) emphasising their relationship relating "via either perceptual resemblance or natural association to the referent"; as such they are semantically motivated signs that "act as a crutch to help people establish shared meanings" (p. 244). The children's iconic signs including tallies, wavy or zigzag lines (signifying writing), letter and numeral-like signs, crosses and dots (often used to refer to uncounted quantities), ticks and arrows, letters, and numerals. Occasionally, a child's drawings resembled concrete items to which they referred, constituting an equality relationship between object and sign (in terms of Cassirer's perspective, Cassirer, 1923).

Emma had modelled tallies in meaningful contexts and subsequently several children explored their use: for example, Isaac represented the quantity of pancakes each child in his group wanted, making a series of circular marks (abstractions of concrete objects). On another occasion, David, Isaac, and Jayden decided to check people in and out as they entered or left the nursery. Using a range of marks and signs, Isaac drew a cross, explaining to an adult who entered "That means you work here." In this instance, Isaac used a cross as a tally.

Another day, David enumerated members of his family, naming each line he drew. Shereen drew tallies for items on her shopping list, counting each with confidence to 20. Tallies are usually regarded as mathematical and associated with one of Gelman and Gallistel's (1986) five counting principles; in one-to-one counting, objects are itemised and only one number assigned to one item. The children's use of tallies indicates that their signs are based on their point of view (counting itemised objects), neglecting all aspects that fall outside this focus. For these children, tallies appear to have the same value in terms of mathematical development. Tallies, however, are more abstract than drawings (iconic signs); their meaning depends on a person's point of view of enumeration. The use of tallies indicates movement towards abstraction from Cassirer's perspective (Cassirer, 1923) suggesting objects are now seen from a specific point of view, i.e., as countable items, rather than depicted as an amorphous collection.

Numeral-like signs The abstract signs of writing and mathematics are discrete yet share some features, and children may occasionally confuse signs of their systems (Bialystok, 1992; Carruthers \& Worthington, 2006; Tolchinsky, 2003): understandings gradually emerge "as they learn to differentiate between their shapes" (Neumann \& Neumann, 2014, p. 1144).

Playing builders, Isaac wrote a letter or numeral-like sign on a play-cheque (Fig. 2) explaining "A cheque for $£ 500.00$, for all the jobs I've done at my house"; Isaac's focus on the monetary aspect of the situation makes it abstract. As a young child beginning to communicate through graphicacy, Isaac had only recently begun to use alphanumerical signs, and we cannot assume that he consistently used the same sign to represent "£500.00", or that he had a conceptual understanding of what this amount represents. Isaac's sign is conceived as a sign in an early stage of development.

As with writing, children must confront multimodal aspects of mathematical notations and the potentials or affordances of particular signs (Worthington \& van Oers, 2017). Signs' orientation serves as graphic organisers, impacting on how they are understood, such as the position of numerals in two-digit numbers. 


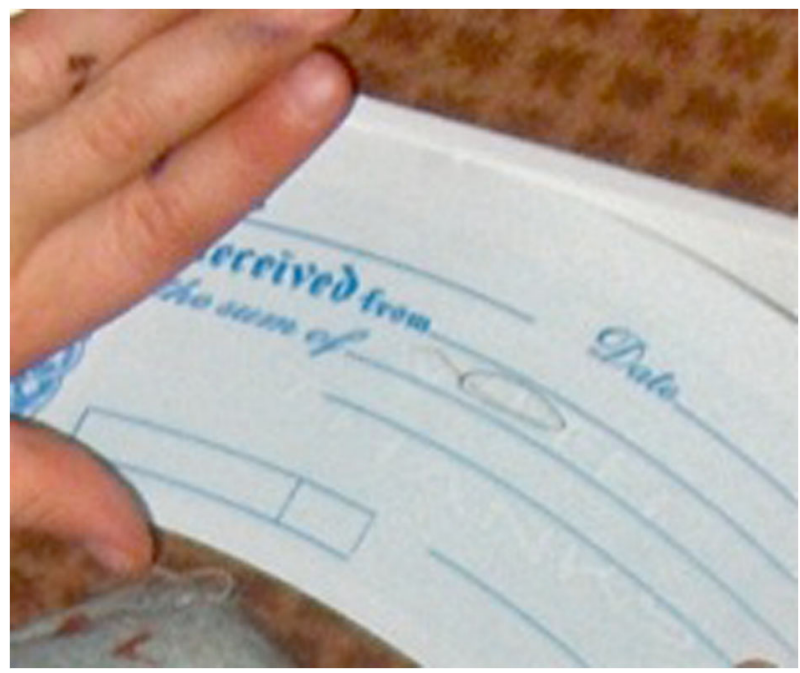

Fig. 2 Isaac's cheque (Worthington, 2018)

\subsection{Symbolic modes}

$12.9 \%$ of signs were symbolic, their meanings (especially when viewed from their contexts) more readily transparent to others. Fay et al. (2014) explain that complex representations "become graphically simpler, and the iconic components depict[ed] [...] become more symbolic" with repeated use, "iconicity moving from the level of the sign to the level of the system" (pp. 251-252).

Of the three focal children, Elizabeth and Shereen wrote numerals to nine, Shereen also writing "14". Large numbers and quantities often intrigue young children, and proud that she could also write "100", Elizabeth used the written number as an abstraction representing (for her) a "big number", although we cannot assume that she understood the exact amount represented. David and Oliver had also begun to write standard numerals. This is of particular interest since multiple researchers have identified relationships between children's early use of numerical symbols and subsequent longitudinal achievement (Merkley \& Ansari, 2016). In her study, in preschools, Munn (1995) identified a relationship between children's understandings and achievement in recognising numerals and letters: the progress made during their first year of primary school "strongly related to the understanding of symbols they had brought with them at school entry", suggesting, "that the important developments taking place concerned the children's understanding of symbols as communicative systems" (p. 217).

\subsection{Indexical}

Of all the children's signs, $18.7 \%$ were indexical, most drawing attention to features and meanings of their signs:

Shereen's arrow (Fig. 3) signifies direction in her "treasure map": Shereen described the route, pointing to indicate the direction. Isaac drew arrows on his collaborative maps, explaining "These are arrows to say, "go this way", and at home drew a double-headed arrow indicating turning left or right at the " $T$ " junction at the end of his road. Isaac's cultural knowledge of maps originated from his father's interest; many maps were displayed and frequently discussed at home. During the first author's home visit, Isaac proudly showed an informal map he had drawn of the city's roads, 


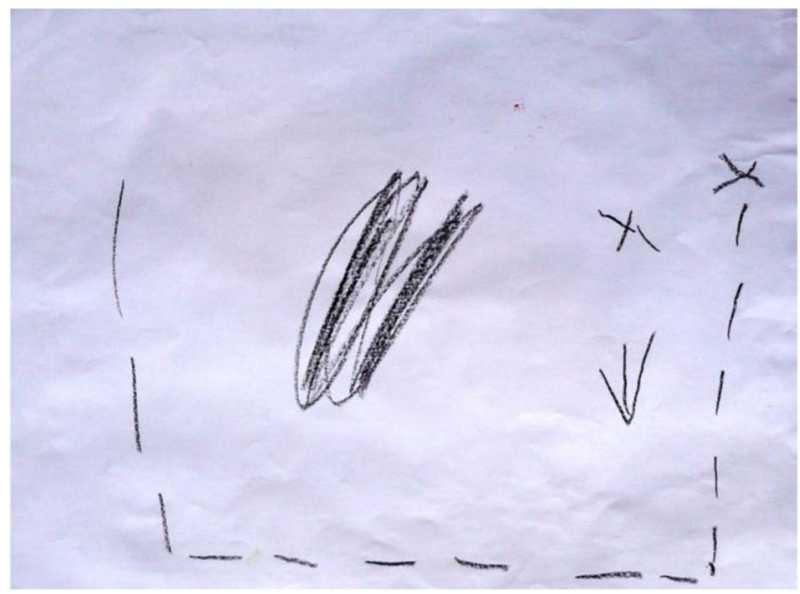

Fig. 3 Shereen's arrow indicates the direction to take

pointing to his home's location and the route travelled to his nursery school each day. Isaac's interest in directions and locations extended to using a compass. Visiting the forest, Isaac told an adult, "I think we're going west... That way is south". Concerned that they might be lost, Isaac asked, "Are we north or south? This is a mystery path! I don't want to go south - it will go to Africa and my bedtime's at six o'clock". In his subtraction (following Fig. 5), David pointed to the marks he was about to rub out, his pointing an example of indexicality. In our view, pointing is the simplest and most clear form of abstraction for young children as it creates joint attention and articulates/ highlights one (and only one) point of view.

Our data suggests that the range of signs the children employed across Pierce's semiotic modes appear to contribute to their understandings as they moved towards an abstract symbolic mode. More research is needed.

RESEARCH QUESTION 2: How does children's intention-reading relate to increase in acquisition of the abstract symbolic language of mathematics?

Joint activities such as collaborative pretend play enable children to discern another's intentions (Tomasello, 2005, pp. 5-6), helping them discern how they might contribute to their shared play through imitation or emulation. Imitation (of behaviour) suggests faithful copying, whereas emulation (of actions) points to the child's adaptive use of signs. In our data, we looked for events that show how children observed others in order to find how they might use the signs in their own activities and communication.

Oliver was playing with Isaac (a focal child); their pretence triggered by Isaac's recent experience of using an electronic card-reader in a city car park and linked to his considerable knowledge of technologies.

saac used scribble-marks to signify his parking signs, explaining, "This says 'swipe here with your special code card'. Adding further marks he explained 'This is the bell if you don't have a sticker and someone can let you in'. It says, 'Press here'. This is for lorries and deliveries. It opens automatically, it's a camera."

Oliver's teacher noted, "Oliver watches and waits before deciding to participate," seemingly to determine Isaac's intentions before he contributed to their play. Although Oliver had not shared 


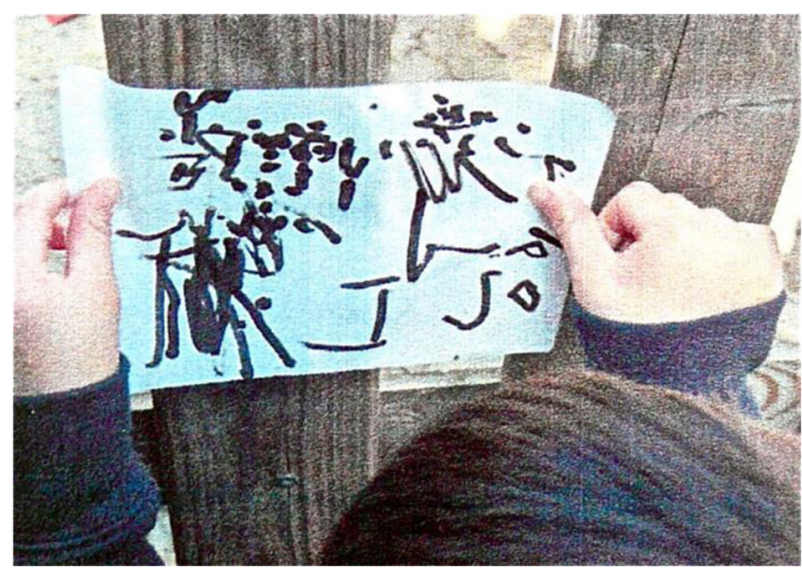

Fig. 4 Oliver's car-park entry sign

Isaac's experience of visiting the same car park, his ability to read Isaac's intentions enabled him to decide how he might contribute to their shared play.

Oliver begins by drawing dots and letter-like signs, followed by several ticks (Fig. 4), explaining, 'These are ticks. When there are three ticks you can go, when there are two you can't go that way [pointing]. I've made two ticks - that means you are not allowed', then pointing in the opposite direction, 'people allowed in that way'. Continuing their play, when another child attempted to access their car park, Oliver referred to his sign.

Oliver had begun to focus on specific meanings, neglecting all aspects that fall outside this focus and emulating Isaac's idea of making a sign but not imitating his marks. Emulation suggests pedagogy through peer learning (Csibra \& Gergely, 2011). ${ }^{12}$ Oliver's use of ticks shows that he is consistently working from a point of view of communicating quantity in this context.

Early calculation In another example of joint attention, Shereen (a focal child) represented her thinking about items sold in her pretend café (Fig. 5), her teacher and David watching.

Pointing to the figures she'd drawn, Shereen explained, "This is me and my Daddy at the café". Drawing a flower and a heart above them, and five cakes on the left, she asked a friend "You like some cake?" and following her friend's affirmation, Shereen rubbed out one cake to show it had been sold. ${ }^{13}$ Repeating the same question, when her teacher also replied "yes" Shereen rubbed out another cake remarking "Three left".

Whilst exploring a calculation was unexpected for such a young child, Shereen's combination of meaningful elements highlights children's innovative early strategies for written calculations. Shereen's action of rubbing-out (i.e., subtracting) cakes, suggests its function as an operand. Tomasello (2005) observes that for young children "linguistic competence is most

\footnotetext{
${ }^{12}$ Csibra and Gergely (2011) propose that the cognitive mechanisms enabling "the transmission of cultural knowledge by communication between individuals [...] represent[ing] an evolutionary adaptation along the hominin lineage", maintaining that children are the most obvious beneficiaries of such a system (p. 1149).

${ }^{13}$ It was unclear to what the number "14" at the top referred.
} 
Fig. 5 Subtracting cakes

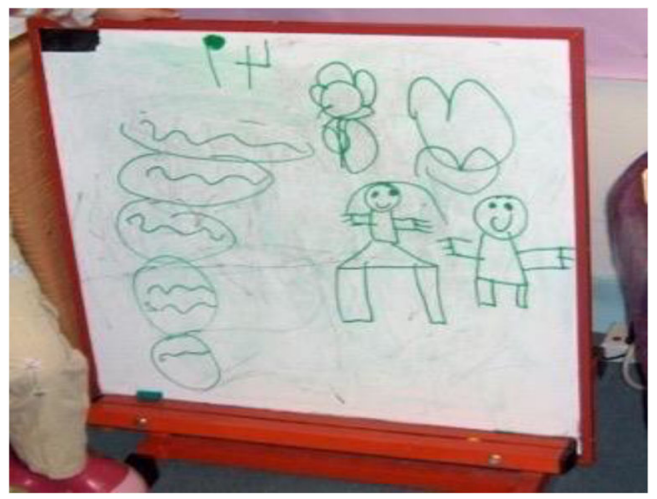

accurately characterized [...] as an inventory of relatively isolated, item-based" constructions: development "proceeds gradually and in piecemeal fashion, with some constructions becoming abstract more rapidly than others" (p. 140/142).

Using the same strategy, David drew himself and Shereen in a café and made several small marks, detailing items to which each referred. Inviting Shereen to "visit" his café, she "ordered" one cake and a cold coffee. David pointed to several small marks, then rubbed them out to signify their removal saying, "here you go. I have to rub them away 'cos they're gone from the café". David had clearly benefitted from reading Shereen's intentions within their joint attentional frame his "ability to culturally (imitatively) learn the intentional actions of others" (Tomasello, 2005, p. 3). Both Oliver and Shereen's examples show some movement towards abstract signs (construed by a previously taken point of view).

The findings of question 2 highlight the importance of pretend play in supporting a form of social learning. Such contexts provide a reciprocal relationship between children playing and interacting, showing how intention-reading relates to increases in their acquisition of the abstract symbolic language of mathematics.

RESEARCH QUESTION 3: How does children's pattern-finding support their increasing grammaticisation?

To identify examples of pattern-finding, we searched the children's graphics (drawing, writing, maps, and mathematical), finding that several included dots, crosses, and arrows for specific purposes, identifying these repeated sign-function units as examples of patternfinding. Grammaticisation was identified as the structure of the patterns.

Tomasello (2005) regards pattern-finding as categorisation, children using their skills "on the functional (or meaning) side of things" (p. 30). To learn conventional, culturally accepted uses of particular signs, children need to distinguish signs in many examples in various situations, but "also see patterns in the way adults use a particular form communicatively across different usage events" (pp. 30-31). Children appear to understand that only a specific graphical sign will fit their immediate communicative purpose, intuitively selecting the most suitable from their personal lexicons. This can be seen in the data, children generally use crosses to signify "none" or "no", dots to signify lots and arrows to denote direction. As the findings of question 1 show, many children using crosses appeared to understand absence or nothing, prior to appreciating that they can represent these concepts by zero (Merritt, DeWind, \& Brannon, 2012).

Identifying patterns of contexts in which crosses are used, individuals sometimes modified their signs for emphasis: for example, whilst playing café, Shereen asked Madison if she wanted some food. When Madison shook her head, Shereen wrote a series of crosses, retorting 
"You not very hungry?" On another occasion, David wrote two large crosses on paper, asserting "No more children getting in our car!" both examples signifying emphatic negatives, highlighting multimodal aspects of their signs. ${ }^{14}$ These examples show children's use of crosses as logographic signs in which the meaning of a word or phrase is encoded in the visual symbol. Shereen's calculation (Fig. 5) implies a pattern of layout and a means of subtracting that David was able to discern and emulate. Tomasello (2005) explains that children "cut and paste" functionally appropriate pieces of language" (as David did) that they have learned or created (p. 321). Children seem to recognise that adults expect them to use graphical signs to convey meaning, although adults may not always understand the meanings of their inscriptions without their verbal explanations.

Lexicons Our data suggest that children of this age already have a repertoire of signs that they subsequently combine in mathematical communication. There was variability in the children's use of signs: Elizabeth and Shereen (two focal children) used most graphical signs across all their literacies, and the greatest number of abstract symbolic signs: both wrote letters of the alphabet (capital and lower-case), and most abstract numerals. Isaac's (a focal child) particular strength was his knowledge of environmental signage on which he often drew in the nursery. The remaining non-focal children varied in their use of signs across all literacies, David doing so most often, and (of the non-focal children) having the largest lexicons of signs, although the quantity of his abstract symbolic numerals was small.

Whilst the sample size is small, the findings suggest a shift over time to increasingly using abstract signs from the established mathematical system, highlighting how "basic conceptual categories that derive from everyday experiences develop into predictable structures that are used automatically" (Lancaster, 2014, p. 35). Though we have to avoid sweeping conclusions, these findings affirm our expectation that as children freely engage in graphicacy in all contexts, they are likely to progress towards standard mathematical patterns of signs.

\section{Discussion}

This study is part of a larger research project into the genesis of mathematical semiosis in early childhood. The aim of the current study is to investigate the emergence of abstract thinking about aspects of mathematics in young children's graphical communications, by thoroughly interrogating data from a nursery school in which an emergent approach to learning mathematics is well understood and supported.

Early childhood is an important period in children's lives. In our earlier study (Worthington \& van Oers, 2016), we found that free pretend play of young children often triggered spontaneous interest in and discussions about aspects of their mathematical cultural knowledge.

There has long been recognition that when traditionally taught, young children find the abstract symbolic language of mathematics challenging. Our data-analysis showed that the children's use of signs in mathematical contexts increased during the year: all used iconic signs, and by the end of the year, some had begun to adopt standard abstract symbols. Frequent sign-use (including letters and numerals) across all the children's literacies appeared to be an

${ }^{14}$ Such signs are suggestive of emphasis in oral speech. 
important factor in developing mathematical abstractions for communication about quantity, transformations, measurement and space, etc. On the basis of Munn's article (Munn, 1995), we can speculate on substantial links between early understanding and later achievement.

This study ascertained that features of usage-based language acquisition were evident in the children's early mathematical inscriptions, and how intention-reading related to their acquisition of the abstract symbolic language of mathematics, helping them understand, imitate, and emulate visual signs of more mature users. Analysis showed that some children identified patterns of signs that best fitted their communicative intentions, employing individual signs across diverse texts. For example, children employed crosses in various contexts to signify absence or nothing, used arrows in various directional contexts and similar layout and strategies for their subtractions: other examples include dots, ticks (as in Fig. 1), letters, and numerals.

Given occurrences of such transferrals, we cautiously conjecture that children's expanding lexicons benefit their ability to select appropriate signs from one context to "fit" in another, and that this expansion contributes to the grammaticisation of mathematical inscriptions. Tomasello (2005) proposes that it is best to see children's signs as "growing gradually in abstraction over time as more and more relevant exemplars are encountered and assimilated" (p. 316, emphasis added). These findings draw attention to the compelling value of the usagebased theory for understanding children's early mathematical abstractions and have implications for the mathematisation of children's early signs (Worthington, Dobber, \& Oers, Submitted) in future practices.

The emergence of mathematical abstraction is viewed here from an early point in children's progression towards the fully abstract symbolic language of mathematics. Children's home cultural knowledge and effective socio-cultural contexts contribute to the free exchange of ideas through speech and text, regarding objects that are generally acknowledged as mathematical (although at this age children themselves will not acknowledge their signs as mathematical). Together, with our earlier studies (e.g., Carruthers \& Worthington, 2006; Worthington \& van Oers, 2017), these findings suggest a close relationship in learning the two alphanumeric symbol systems, provided children have freedom to use personal graphical communications to signify mathematical meanings. Moreover, the finding that several children made use of standard numerical symbols (predictive of subsequent mathematical achievement in school, Munn, 1995) points to the value of this approach and the teachers' expertise.

We consider that the values and democratic culture of this nursery school precipitated the children's interest in the use of signs to communicate their thinking in mathematical contexts. The headteacher created a rich community of learners, instigating a culture of staff research and dialogue that can be seen in the following characteristics:

- Adults' support of children's self-initiated ideas and how they express them provided positive messages, confirming for them that their communicative use is meaningful, relevant, and valued, and contributing to their agency.

- Teachers' frequent modelling of signs within authentic contexts provided new signs on which the children might draw, increasing their sign repertoires.

- Contexts in which children experimented with signs and "read" others" intentions helped them discern patterns of sign-use across all their literacies.

- Children's frequent graphical inscriptions stimulated their increased use of letters and numerical symbols for communicative purposes. 
- The teachers' deep understandings of pretend play contributed to its quality, providing meaningful opportunities for children to explore their cultural mathematical knowledge: their understanding of the children's home cultural knowledge supported this.

These findings commend learning cultures in early-year classrooms in which graphicacy, mathematics, and pretend play are highly valued and understood.

\subsection{Limitations}

Data were gathered in a nursery school embracing open approaches to graphical inscriptions and the teaching of mathematical signs: since we know of no other nursery schools in England consistently working in this way, and due also to the small numbers of children, empirical generalisations are not possible. The problem of "transferability" can be solved in three ways (1) through "professionalisation" of teachers on how to interact with young children and their use of marks, etc. (e.g., Pompert, 2012); (2) through methodological criteria, giving in-depth specifications on visibility, comprehensibility, and acceptability (Akkerman, Admiraal, Brekelmans, \& Oost, 2006), and (3) through "theoretical generalisation." 15 Working closely with teachers to develop their professionalism, Carruthers and Worthington (e.g., Carruthers \& Worthington, 2011; Carruthers, 2012) identified many instances of transferability that provided comparative results. Willig (2013) posits that conducting studies "in sufficient numbers can give rise to statements about general trends and the typicality of occurrences" (p. 109). Hence, upscaling the study with a larger number of pupils is necessary to determine if our outcomes can be reliably reproduced. In spite of these limitations, the findings from this study will add to knowledge of the emergence of abstraction, the early evolution of children's mathematical communications through graphical signs, and some of the processes involved in their developing understandings.

\section{Conclusion}

This study focused on documenting the types of signs young children make to represent and communicate about their mathematical thinking, and to determine the extent to which features of usage-based language acquisition are evident in children's early mathematical inscriptions. The empirical findings, analysed from our point of view of "abstraction", can indeed highlight the appearance of abstract thinking in young children, a previously unknown finding. The children's movement from iconic towards abstract symbols suggests they are making connections with their existing and new knowledge. "Reading" their peers' intentions and intuitively locating patterns of sign-use appears to be integral to this development. The findings suggest that these personally meaningful and authentic beginnings support the emergence of the symbolic language of mathematics early in childhood. They indicate that problems identified by Ginsburg (1977), Hughes (1986), and many others may be avoided, allowing children's mathematical potentials to be more fully realised. Especially

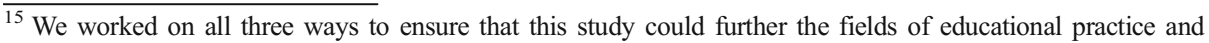
research.
} 
interesting is that the children who most often used graphical signs to communicate in all literacies most often used numerical symbols, a feature identified as predictive of subsequent success in mathematics in school.

Curriculum reform based on recent research in this significant area of mathematics is sorely needed to further pedagogical understanding, and to deepen teachers' appreciation of children's beginnings with mathematical signs, and the development of their powerful mathematical thinking.

Acknowledgements Sincere thanks are extended to headteacher Elizabeth Carruthers, staff, children, and parents of Redcliffe maintained nursery school, Bristol, for generously sharing the children's rich mathematical thinking, play, and graphicacy.

\section{Compliance with ethical standards}

Conflict of interest The authors declare that they have no conflict of interest.

Open Access This article is distributed under the terms of the Creative Commons Attribution 4.0 International License (http://creativecommons.org/licenses/by/4.0/), which permits unrestricted use, distribution, and reproduction in any medium, provided you give appropriate credit to the original author(s) and the source, provide a link to the Creative Commons license, and indicate if changes were made.

\section{References}

Akkerman, S., Admiraal, W., Brekelmans, M., \& Oost, H. (2006). Auditing quality of research in social sciences. Quality \& Quantity, 42(2), 257-274. https://doi.org/10.1007/s11135-006-9044-4

BERA. (2011). Ethical guidelines for educational research. London: BERA. Retrieved from https://www. bera.ac.uk/wp-content/uploads/2014/02/BERA-Ethical-Guidelines-2011.pdf?noredirect=1

Bialystok, E. (1992). The symbolic representation of letters and numbers. Cognitive Development, 7(3), 301316. https://doi.org/10.1016/0885-2014(92)90018-M

Brizuela, B. (2004). Mathematical development in young children: Exploring notations. New York, NY: Teachers College Press.

Buchler, J. (Ed.). (1955). Philosophical writings of Peirce. London, UK: Dover Publications.

Carruthers, E. (2012). Are the children thinking mathematically? In M. MacAteer (Ed.), Improving primary mathematics: Teaching and learning (pp. 192-212). Maidenhead, UK: Open University Press.

Carruthers, E. (2015). Listening to children's mathematics in school. In B. Perry, A. MacDonald, \& A. Gervasoni (Eds.), Mathematics and transition to school: International perspectives (pp. 313-330). Sydney, Australia: Springer.

Carruthers, E. (in progress) The pedagogy of children's mathematical graphics. Doctoral dissertation: University of Bristol.

Carruthers, E., \& Worthington, M. (2005). Making sense of mathematical graphics: The development of understanding abstract symbolism. European Early Childhood Education Research Journal, 13(1), 57-79. https://doi.org/10.1080/13502930585209561

Carruthers, E., \& Worthington, M. (2006). Children's mathematics: Making marks, making meaning (2nd ed.). London, UK: Sage Publications.

Carruthers, E., \& Worthington, M. (2011). Understanding children's mathematical graphics: Beginnings in play. Maidenhead: Open University Press.

Cassirer, E. (1923). Substance and function and Einstein's theory of relativity. New York, NY: Dover.

Clay, M. (1975). What did I write? Beginning writing behaviour. Portsmouth, NH: Heinemann.

Cobb, P., Yackel, E., \& McClain, K. (Eds.). (2000). Symbolizing and communicating in mathematics classrooms. Mahwah, NJ: Lawrence Erlbaum Associates, Publishers.

Csibra, G., \& Gergely, G. (2011). Natural pedagogy as evolutionary adaptation. Philosophical Transactions of the Royal Society B, 366, 1149-1157. https://doi.org/10.1098/rstb.2010.0319 
Department for Education (DfE), (2017). Statutory framework for the early years foundation stage. London: DfE. Retrieved from: https://assets.publishing.service.gov.uk/government/uploads/system/uploads/attachment_ data/file/596629/EYFS_STATUTORY_FRAMEWORK_2017.pdf

Ernest, P. (2005). Activity and creativity in the semiotics of learning mathematics. In M. Hoffmann, J. Lenhard, \& F. Seeger (Eds.), Activity and sign: Grounding mathematics education (pp. 23-34). London, UK: Springer.

Fay, N., Ellison, M., \& Garrod, S. (2014). Iconicity: From sign to system in human communication and language. Pragmatics \& Cognition, 22(2), 244-263. https://doi.org/10.1075/pc.22.2.05fay

Geertz, C. (1973). The interpretation of cultures. Peterborough: Fontana Press.

Gelman, R., \& Gallistel, C. (1986). The child's understanding of number (2nd ed.). Harvard, MA: Harvard University Press.

Ginsburg, H. (1977). Children's arithmetic. New York, NY: van Nostrand.

Hiebert, J. (1984). Children's mathematical learning: The struggle to link form to understanding. Elementary School Journal, 84(5), 496-513. https://doi.org/10.1086/461380

Hughes, M. (1986). Children and number. Oxford, UK: Blackwell.

Kress, G. (1997). Before writing: Re-thinking the paths to literacy. London: Routledge.

Lancaster, L. (2014). The emergence of symbolic principles: The distribution of mind in early sign making. Biosemiotics, 7(1), 29-47. https://doi.org/10.1007/s12304-013-9195-3

Langacker, R. (2008). Cognitive grammar: A basic introduction. Oxford, UK: Oxford University Press.

MacDonald, A. (2013). Young children's ideas about measurement: What does a kindergarten student consider 'measuring' to be? Australian Primary Mathematics Classroom, 18(1), 3-7.

Machón, A. (2013). Children's drawings: The genesis and nature of graphic representation. Madrid, Spain: Fibulas Publishers.

Merkley, R., \& Ansari, D. (2016). Why numerical symbols count in the development of mathematical skills: Evidence from brain and behavior. Current Opinion in Behavioral Sciences, 10, 14-20. https://doi. org/10.1016/j.cobeha.2016.04.006

Merritt, D., DeWind, N., \& Brannon, E. (2012). Comparative cognition of number recognition. In E. A. Wasserman \& T. R. Zentall (Eds.), The Oxford handbook of comparative cognition (pp. 451-476). Maidenhead, UK: Open University Press.

Moffett, P., \& Eaton, P. (2018). The impact of the Promoting Early Number Talk project on the development of abstract representation in mathematics. European Early Childhood Education Research Journal, 26(4), 547561. https://doi.org/10.1080/1350293X.2018.1487166.

Morgan, C. (2006). What does social semiotics have to offer mathematics education research? Educational Studies in Mathematics, 61(1-2), 219-245. https://doi.org/10.1007/s10649-006-5477-x

Munn, P. (1994). The early development of literacy and numeracy skills. European Early Childhood Education Research Journal, 4(1), 5-18. https://doi.org/10.1080/13502939485207491

Munn, P. (1995). The role of organised preschool learning environments in literacy and numeracy development. Research Papers in Education, 10(2), 217-252. https://doi.org/10.1080 $/ 0267152950100207$

Neumann, M. M., \& Neumann, D. L. (2014). A measure of emerging print knowledge in young children. Early Child Development and Care, 184(8), 1142-1159. https://doi.org/10.1080/03004430.2013.853054

Nunes, T. (1993). The socio-cultural context of mathematical thinking: Research findings and educational implications. In A. J. Bishop, K. Hart, S. Lerman, \& T. Nunes (Eds.), Significant influences on children's learning of mathematics (pp. 27-42). Paris: UNESCO.

Pompert, B. (2012). Creating knowledge and practice in the classroom. In B. van Oers (Ed.), Developmental education for young children: Concept, practice and implementation. Dordrecht, the Netherlands: Springer.

Presmeg, N. (2006). Semiotics and the "connections" standard: Significance of semiotics for teachers of mathematics. Educational Studies in Mathematics, 61(1-2), 163-182. https://doi.org/10.1007/s10649-006-3365-z

Price, S., Jewitt, C., \& Crescenci, L. (2015). The role of iPads in pre-school children's mark making development. Computers in Education, 87, 131-141. https://doi.org/10.1016/j.compedu.2015.04.003

Sarama, J., \& Clements, D. H. (2008). Mathematics in early childhood. In O. N. Saracho \& B. Spodek (Eds.), Contemporary perspectives on mathematics in early childhood education (pp. 67-94). Charlotte, NC: Information Age Publishing.

Tolchinsky, L. (2003). The cradle of culture and what children know about writing and numbers before being taught. Mahwah, NJ: Lawrence Erlbaum Associates.

Tomasello, M. (2005). Constructing a language: A usage-based theory of language acquisition. Cambridge, MA: Harvard University Press.

van Oers, B. (2001). Educational forms of initiation in a mathematical culture. Educational Studies in Mathematics, 46(1-3), 59-85. https://doi.org/10.1023/A:1014031507535

van Oers, B. (2012). Meaningful cultural learning by imitative participation: The case of abstractthinking in primary school. Human Development, 55(1), 136-158. https://doi.org/10.1159/000339293 
VU University. (2014). Ethical review regulations. Amsterdam, the Netherlands: Faculty of Psychology and Education, VU University.

Vygotsky, L. S. (1978). Mind in society: The development of higher psychological processes. Cambridge, MA: Harvard University Press.

Werner, H., \& Kaplan, B. (1963). Symbol formation. An organismic-developmental approach to the psychology of language. London, UK: Lawrence Erlbaum Associates.

Williams, S. P. (2008). Final report of the independent review of mathematics teaching in early years settings and primary schools. London, UK: DCSF.

Willig, C. (2013). Introducing qualitative research in psychology (3rd ed.). Maidenhead, UK: Open University Press / McGraw-Hill Education.

Worthington, M. (2009). Fish in the water of culture: Signs and symbols in young children's drawing. The Psychology of Education Review, 33(1), 37-46.

Worthington, M. (2018). Funds of knowledge: Children's cultural ways of knowing mathematics. In M.-Y. Lai, T. Muir, \& V. Kinnear (Eds.), Forging connections in early mathematics teaching and learning (pp. 239258). Singapore: Springer.

Worthington, M., Dobber, M., \& van Oers, B. (Submitted). Intertextuality and the advance of mathematisation in young children's inscriptions.

Worthington, M., \& van Oers, B. (2016). Pretend play and the cultural foundations of mathematics. European Early Childhood Education Research Journal, 24(1), 51-66. https://doi.org/10.1080/1350293 X.2015.1120520

Worthington, M., \& van Oers, B. (2017). Children's social literacies: Meaning-making and the emergence of graphical symbols in pretence. International Journal of Early Childhood Literacy, 24(1), 147-175. https://doi.org/10.1177/1468798415618534

Zaharlick, A. (1992). Ethnography in anthropology and its value for education. Theory Into Practice, 31(2), 116125. https://doi.org/10.1080/00405849209543532

Publisher's note Springer Nature remains neutral with regard to jurisdictional claims in published maps and institutional affiliations. 